\title{
Elderly Veterans Receiving Care at a Veterans Affairs Medical Center While Enrolled in Medicare-Financed HMOs
}

\author{
Is the Taxpayer Paying Twice? \\ Leigh J. Passman, MD, PhD, Rosa Elena Garcia, MPH, Lynn Campbell, BS, \\ Eric Winter, $R_{N}, P H N$
}

\begin{abstract}
Elderly veterans who visit our Veterans Affairs (VA) Medical Center primary care clinic often mention they are enrolled in HMOs. Approximately $20 \%$ of patients hospitalized at our facility report health insurance coverage. Of 1,000 hospitalizations during a 6-month period in which veterans reported insurance coverage, 337 involved elderly veterans. Of these 337 hospitalizations, $218(65 \%)$ were for 174 veterans who stated they were enrolled in a Medicare-financed HMO. The VA's Medical Care Cost Recovery Program deemed only 46 (21\%) of the hospitalizations billable and received reimbursement for 20 (9\%). Thus, the VA is providing costly services already paid for by the Health Care Financing Administration under prepaid capitation contracts, and recovers minimal reimbursement from the HMOs.
\end{abstract}

KEY WORDS: veterans; elderly; Medicare; HMOs; health care financing.

J GEN INTERN MED 1997;12:247-249.

E nrollment of Medicare beneficiaries in HMOs under capitated risk contracts has been touted as one approach to constrain the growth in Medicare expenditures. ${ }^{1}$ Enrollment of Medicare beneficiaries in HMOs has accelerated in recent years: 9\% or 3.8 million aged Americans are now enrolled in HMOs under Medicare risk contracts. ${ }^{2,3}$

Physicians from Department of Veterans Affairs (VA) Medical Centers in California, Florida, Kansas, New Mexico, and other states have noted an increase in the number of elderly veteran patients who seek care at VA facilities while enrolled in HMOs (personal communications at the

Received from the Division of General Internal Medicine (LJP, REG) and the Medical Care Cost Recovery Program (LC, EW), West Los Angeles (Calif.) Veterans Affairs Medical Center, and the University of California-Los Angeles School of Medicine (LJP, REG).

Presented in part at the 19th annual meeting of the Society of General Internal Medicine, Washington, DC, May 2-4, 1996.

Address correspondence and reprint requests to Dr. Passman: Department of Medicine (W111G), West Los Angeles VA Medical Center, 11301 Wilshire Blvd., Los Angeles, CA 90073.
1996 SGIM national meeting). Two studies at individual VA facilities found that HMO enrollment ranged from $10 \%$ among veterans of all ages, ${ }^{4}$ to about $25 \%$ among elderly veterans. $^{5}$

We quantified the extent to which elderly veterans hospitalized at one Southern California VA Medical Center reported HMO enrollment. We then determined the reimbursement that the VA's Medical Care Cost Recovery (MCCR) Program received from HMOs for the inpatient care provided to these HMO enrollees.

\section{METHODS}

Patients hospitalized at this VA facility are routinely asked about health insurance or health plan coverage at the time of admission; this information is forwarded to the MCCR Program staff to facilitate billing of third-party payers. We reviewed medical, surgical, and neurology hospitalizations in which a discharge occurred during the 6-month period between December 1993 and May 1994, and focused on those hospitalizations in which an elderly veteran (defined as age 65 or older) reported such coverage. For those who specified HMO coverage, we obtained further demographic and clinical data from the VA's inpatient treatment file.

Historically, the MCCR Program staff has concentrated its billing and collection efforts on care for conditions that are not connected to the veteran's military service. HMOs generally contest payment for elective or nonemergent care not previously authorized, so MCCR Program staff often do not pursue HMO reimbursement for such care. We reviewed billing and collections for those hospitalizations in which reimbursement was sought from the HMO.

\section{RESULTS}

\section{Veterans and Their Hospitalizations}

Veterans of all ages disclosed insurance or health plan coverage in $1,000(20.5 \%)$ of 4,879 hospitalizations. Elderly veterans reported such coverage in $337(17.5 \%)$ of their 
Table 1. Sociodemographic Characteristics of 174 Elderly Veterans

\begin{tabular}{|c|c|c|}
\hline Characteristic & $n$ & $\%$ of 174 \\
\hline \multicolumn{3}{|l|}{ Gender } \\
\hline Male & 170 & 97.7 \\
\hline Female & 4 & 2.3 \\
\hline \multicolumn{3}{|l|}{ Race/ethnicity } \\
\hline White & 98 & 56.3 \\
\hline African-American & 49 & 28.2 \\
\hline Hispanic & 16 & 9.2 \\
\hline Asian/Pacific Islander & 6 & 3.4 \\
\hline Mixed/Not recorded & 5 & 2.9 \\
\hline \multicolumn{3}{|l|}{ Marital status } \\
\hline Married & 99 & 56.9 \\
\hline Divorced/separated & 41 & 23.6 \\
\hline Widow/widower & 16 & 9.2 \\
\hline Single/never married & 16 & 9.2 \\
\hline Not recorded & 2 & 1.1 \\
\hline \multicolumn{3}{|c|}{ Age Categories (mean 75.5 years) } \\
\hline $65-70$ & 44 & 25.3 \\
\hline $71-75$ & 50 & 28.7 \\
\hline $76-80$ & 48 & 27.6 \\
\hline $81-85$ & 16 & 9.2 \\
\hline $86-90$ & 12 & 6.9 \\
\hline$>90$ & 4 & 2.3 \\
\hline \multicolumn{3}{|l|}{ Basis of eligibility } \\
\hline \multicolumn{3}{|l|}{ Service connected } \\
\hline$<50 \%$ & 55 & 31.6 \\
\hline $50-100 \%$ & 19 & 10.9 \\
\hline \multicolumn{3}{|l|}{ Not service connected } \\
\hline Type A* & 55 & 31.6 \\
\hline Type $\mathrm{C}^{\dagger}$ & 14 & 8.0 \\
\hline VA pension & 5 & 2.9 \\
\hline Not known & 24 & 13.8 \\
\hline Not determined & 2 & 1.1 \\
\hline
\end{tabular}

*Type A: Veterans with income of $\$ 19,912$ or less if single or $\$ 23,896$ or less if married or single with one dependent. These veterans must be provided hospital care.

${ }^{\dagger}$ Type C: Veterans who do not have service-connected conditions and whose incomes exceed the ceiling. Medical care is discretionary and may be provided if space and resources are available.

1,922 discharges. In 218 (64.7\%) of these 337 hospitalizations $-4.5 \%$ of all discharges and $11.3 \%$ of elderly discharges-aged veterans reported enrollment in an HMO.

The 218 discharges were generated by 174 elderly veterans between the ages of 65 and 99. Most were enrolled in FHP (39\%) and Kaiser Permanente (27\%). Smaller percentages were enrolled in PacifiCare's Secure Horizons (15\%), United Health Plan (4\%), CIGNA (3\%), and Care America (3\%).

Table 1 lists the demographic characteristics of these elderly HMO enrollees. The majority (58\%) had no serviceconnected eligibility, and only $11 \%$ had service-connected eligibility rated at $50 \%$ or more.

Most of the 174 HMO enrollees were hospitalized once during the 6-month period, but nearly a quarter had
Table 2. Admitting Diagnoses for 218 Hospitalizations of Elderly Veterans

\begin{tabular}{lcc}
\hline \hline Diagnostic Clusters & $\boldsymbol{n}$ & \% of 218 \\
\hline Coronary artery disease & 14 & 6.4 \\
CVA/TIA* & 11 & 5.0 \\
Angina & 10 & 4.6 \\
Congestive heart failure & 10 & 4.6 \\
Dementia & 10 & 4.6 \\
Renal failure & 10 & 4.6 \\
Chronic obstructive pulmonary disease & 8 & 3.7 \\
Eye conditions & 8 & 3.7 \\
Depression & 7 & 3.2 \\
Pneumonia & 7 & 3.2 \\
Arrhythmia & 6 & 2.8 \\
Cellulitis & 5 & 2.3 \\
Prostate conditions ${ }^{\dagger}$ & 5 & 2.3 \\
Lung cancer & 5 & 2.3 \\
\hline
\end{tabular}

${ }^{*}$ CVA indicates cerebrovascular accident; TIA, transient ischemic attack.

${ }^{\dagger}$ Conditions include prostatitis, prostate cancer, and obstructive uropathies secondary to prostatic hypertrophy.

two, three, or four hospitalizations. Length of stay ranged from 1 to 120 days, with a median of 7 days and a mean of 13 days.

We clustered hospitalizations according to admitting diagnosis. Table 2 presents the 14 most frequent diagnostic clusters which accounted for $53 \%$ of the 218 hospitalizations.

\section{Medical Care Cost Recovery Program Billings and Collections}

MCCR Program staff deemed 172 hospitalizations (79\%) "unbillable," usually because the condition causing admission was connected to the veteran's military service or was for elective or nonemergent care not previously authorized by the HMO. HMOs were billed for 46 hospitalizations (21\%): charges ranged from $\$ 829$ to $\$ 45,062$ (mean \$9126; total \$419,814). Payment was received for 20 cases $(43 \%)$, generating $\$ 137,540$ or $33 \%$ of total billings. Full payment was received for 15 cases; only an emergency department fee or a hospitalization copayment was paid for the other five cases.

\section{DISCUSSION}

Elderly veterans who reported insurance or health plan coverage generated $7 \%$ of all hospitalizations at this VA Medical Center. Two thirds of these hospitalizations, or $4.5 \%$ of the total, involved HMO enrollees. In a state with one of the country's highest rates of HMO enrollment among Medicare beneficiaries (34\%), ${ }^{6}$ this suggests that elderly VA users are opting to enroll in Medicare HMOs rather than purchase Medigap insurance.

With the number of Medicare beneficiaries joining HMOs under capitated risk contracts climbing rapidly, 
the VA will be providing medical services to an increasing number of veterans enrolled in Medicare-financed HMOs. Whereas capitating Medicare expenditures was expected to contain (or at least enhance the predictability of) future Medicare outlays, out-of-plan utilization that occurs at federally financed VA facilities means the federal government pays twice. Although the VA has the authority to bill and collect from third-party payers, actual collections from HMOs are small in relation to the costs incurred by the VA and those averted by the HMO.

In addition to the financial implications, our findings raise other important questions. Many hospitalizations appear to be for exacerbations of chronic conditions. Do elderly HMO enrollees experience or perceive barriers to timely HMO care? Are the copayments that HMOs charge for office visits and medications an incentive for veterans to seek VA care? How is the continuity and quality of HMO care affected when enrollees obtain some care at VA facilities?

Our study has several limitations. First, HMO enrollment was self-reported; confirmation was pursued only for those cases in which MCCR Program staff expected to bill the HMO. Some patients may have been mistaken about coverage or whether it was still in force. Others, however, most likely forgot or concealed HMO enrollment. We suspect our figures understate VA utilization by HMO enrollees.

Second, our study examined only those veterans over age 65; we ignored the one in six Medicare-eligible VA users who are disabled veterans under age $65 .{ }^{7}$ Though relatively few disabled Medicare beneficiaries have enrolled in HMOs, it is possible that some hospitalized disabled veterans not included in our sample were HMO enrollees.

Third, this study examined a 6-month period during fiscal year 1994. Since 1994, HMO enrollment of Medicare beneficiaries in California has increased $46.4 \%^{8}$; thus, the numbers presented here most likely understate the current reality. Finally, this study made no effort to examine ambulatory care or prescription medications provided to veterans enrolled in HMOs, which certainly account for substantial added costs to the VA.

Further research needs to be done to quantify the magnitude of VA utilization by Medicare-eligible veterans enrolled in HMOs nationwide; to understand the reasons veterans who enroll in Medicare-financed HMOs still go to VA facilities; to estimate the duplicate federal spending by the Health Care Financing Administration and the VA and potential excess premiums paid to HMOs; and to explore whether better coordination of these overlapping benefits could improve care and avoid duplicate federal expenditures.

\section{REFERENCES}

1. McMillan A. Trends in Medicare health maintenance organization enrollment: 1986-93. Health Care Fin Rev. 1993;15:135-46.

2. Zaraboso C, Taylor C, Hicks J. Dataview: Medicare managed care: numbers and trends. Health Care Fin Rev. 1996;17:243-61.

3. Health Care Financing Administration. Profiles of Medicare, 30th Anniversary Report. Baltimore, Md: HCFA; April 1996.

4. Yano E, Graham M, Simon B, Lanto AB, Coleman C, Rubenstein LV. Survey of Health and Medical Care for Veterans in Ambulatory Care. (VA-S\#94301) Sepulveda, Calif: Veterans Affairs Medical Center, Evaluation and Decision Support (EDS) Service; 1994.

5. Morgan R, Virnig B, DeVito C. Medicare HMO Membership and Use of VAMC Medical Care. Poster presentation at the 14th annual meeting, VA Health Services Research and Development Service, Washington, DC, February 28-March 1, 1996.

6. Health Care Financing Administration. Medicare Managed Care Contract Report. Baltimore, Md: HCFA, Office of Managed Care; July 1996.

7. U.S. General Accounting Office. Veterans Health Care. Most Care Provided Through Non-VA Programs. Briefing Report to the Ranking Minority Member, Committee on Veteran's Affairs, U.S. Senate. Washington, DC: U.S. General Accounting Office; April 1994. Report No. GAO/HEHS 94-104BR.

8. Health Care Financing Administration. Medicare Managed Care Contract Reports. Baltimore, Md: HCFA, Office of Managed Care; August 1996.

\section{JGIM's E-mail Address}

For Letters to the Editor or for information about submitting manuscripts to JGIM: Walklett@mail.med.upenn.edu 